\title{
O Hormônio de Crescimento na Síndrome de Turner: Dados e Reflexões
}

\begin{abstract}
RESUMO
A baixa estatura é a principal característica na síndrome de Turner (ST). O agravo estatural na ST é precoce e torna-se mais evidente na puberdade. A haploinsuficiência do gene SHOX tem sido implicada como principal fator na definição da estatura de mulheres, no entanto, ainda que a maioria das pacientes não tenha deficiência do hormônio de crescimento, a terapia com $\mathrm{GHr}$ melhora a altura final. Recentemente, tem-se chamado a atenção para a associação entre $\mathrm{GH}$ e câncer. $\mathrm{O}$ risco de câncer nessas pacientes está associado à presença de fragmentos do cromossomo $Y$ que pode levar ao desenvolvimento de gonadoblastoma. Dessa forma, a administração de GHr na ST deve ser feita com cautela. A investigação de seqüências do cromossomo $Y$ deve ser realizada, bem como a gonadectomia profilática nos casos positivos, conferindo maior segurança ao tratamento. (Arq Bras Endocrinol Metab 2008; 52/5:757-764)
\end{abstract}

Descritores: Síndrome de Turner; Hormônio do crescimento; Câncer; Polimorfismo; Imprinting genômico

\section{ABSTRACT}

\section{Growth Hormone Treatment inTurner Syndrome: Data and Reflections.}

Short stature is the major characteristic of Turner syndrome. The statural appeal is premature and become evident in the puberty. Haploinsuficiency of SHOX gene has been related as main factor on final height of these patients. Despite the majority of the patients are not growth hormone deficient, the $\mathrm{GHr}$ therapy improves the final height. Recently, a great number of publications have described the association between $\mathrm{GH}$ and cancer. The cancer risk, in these patients, is mainly associated with the presence of $Y$ chromosome sequences that can lead to the gonadoblastoma development. In conclusion, the $\mathrm{GHr}$ therapy in ST patients deserves caution. The investigation of $\mathrm{Y}$ chromosome sequences should be performed as well as the prophylactic gonadectomy in the positive cases conferring confidence to the treatment. (Arq Bras Endocrinol Metab 2008; 52/5:757-764)

Keywords: Turner Syndrome; Growth hormone; Cancer; Polymorphism; Genomic imprinting

\section{A BAIXA ESTATURA NA SÍNDROME DE TURNER}

D ESDE A DESCRIÇÃo Clássica de Henry Turner, em 1938 (1), que dizia respeito a sete mulheres com sinais físicos peculiares, já se identificava a baixa estatura como um dos principais achados que caracterizavam a síndrome que herdou seu nome. Atualmente, a despeito da identificação crescente de outras múltiplas alterações clínicas na síndrome, apenas a deficiência estrogênica alcança prevalência semelhante à da perda estatural. Esta última chega a revisõo

\author{
Alexis D. Guedes \\ BIANCA BIANCO \\ emmanuela Q. Callou \\ ANa LUIZZA GoMes \\ MÔNICA V. N. LIPAY \\ IEDA T. N. VERRESCHI
}

Disciplina de Endocrinologia do Departamento de Medicina da Universidade Federal de São Paulo (Unifesp), São Paulo, SP Brasil (ADG, BB, EQC, ALG, ITNV); Disciplina de Genética do Departamento de Morfologia e Genética da Unifesp, São Paulo, SP, Brasil (MVNL).

Recebido em 3/6/2008 Aceito em 10/6/2008 
ser encontrada em $95 \%$ a $99 \%$ das mulheres acometidas (2).

Acompanhando curvas que ilustrem a evolução do crescimento natural das mulheres com síndrome de Turner (ST) do nascimento até a idade escolar detectase agravo estatural precoce, porém discreto, que progressivamente acompanha o acréscimo na idade cronológica (3). Tal achado torna-se cada vez mais evidente e tem seu ápice no período da puberdade ( $\mathrm{Fi}$ gura 1). Neste período, a influência hormonal do estrógeno produzido pelos ovários das mulheres normais e a carência deste nas mulheres com ST determinam a diferença de maturação óssea e a aceleração do crescimento do estirão puberal. Como a deficiência estrogênica retarda também o fechamento epifisário, permitindo uma fase de crescimento prolongada, há discreta diluição da perda estatural das mulheres com ST, que, no final do processo, não é suficientemente compensadora, o que fica demonstrado com a diferença estatural final média de $20 \mathrm{~cm}$ entre portadoras da síndrome e mulheres normais (4).

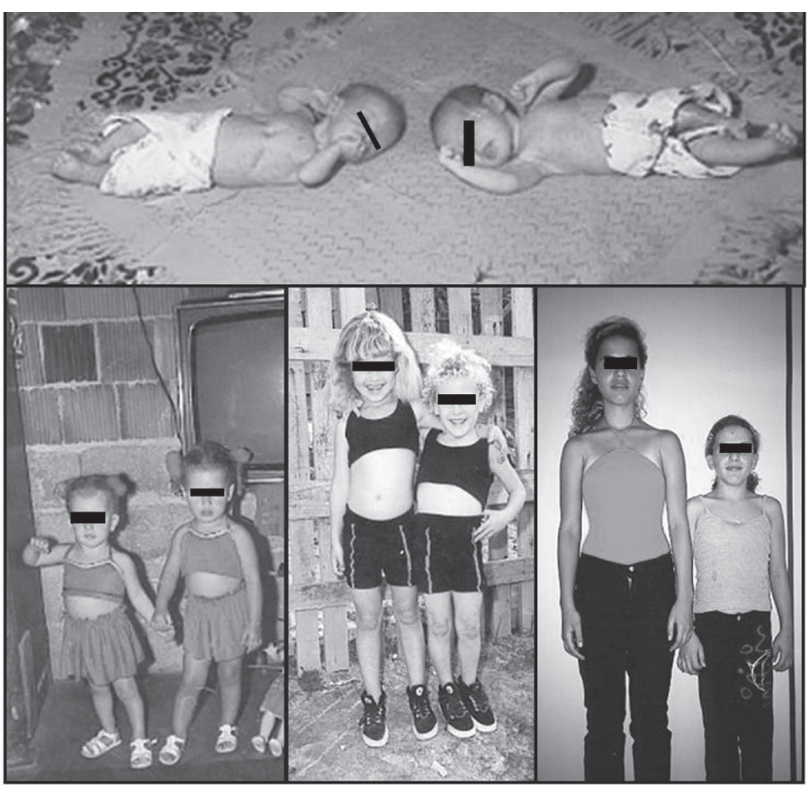

Figura 1. Referência histórica do nascimento a idade pubertária de par de gêmeas discordantes para a ST (com a respectiva autorização materna para uso da imagem).

\section{CAUSA gENÉTICA}

A descoberta do gene SHOX na região pseudoautossômica l (PARl) dos cromossomos sexuais, juntamente com a definição de sua participação no processo de crescimento ósseo, acrescentou muito para a compreensão da baixa estatura na ST (5-7). A região PARl situa-se na porção distal do braço curto de ambos os cromossomos sexuais, $\mathrm{X}$ e $\mathrm{Y}$, e, aparentemente, os 24 genes descritos nesta região não são inativados no $\mathrm{X}$, definindo duas cópias funcionais nos cromossomos sexuais. O gene $\mathrm{SHOX}$ exibe função dosagem-sensível com atuação na maturação e na diferenciação de condrócitos, particularmente em placas de crescimento, e a sua haploinsuficiência, seja por deleção no braço curto de $\mathrm{X}$ ou $\mathrm{Y}$ ou pela perda completa de um destes cromossomos, determina sua expressão inadequada com perdas estaturais e outras alterações ósseas estruturais $(8,9)$.

Desde as primeiras publicações sobre o tema, houve consenso entre especialistas a respeito do papel da haploinsuficiência do gene $S H O X$ como principal fator na definição da estatura das mulheres com ST $(10,11)$, porém, a questão da existência de fatores adicionais contribuintes para este processo gerou algum debate e ainda encontra-se aberta a novas fundamentações (12).

\section{TRATAMENTO COM HORMÔNIO DE CRESCIMENTO RECOMBINANTE (GHr)}

A experiência clínica com hormônio de crescimento recombinante $(\mathrm{GHr})$ é relativamente recente. A Food and Drug Administration (FDA), agência americana de controle de medicações, autorizou o uso do $\mathrm{GHr}$ apenas em 1996. Nessa época, iniciou-se tal terapêutica no Brasil, em virtude da distribuição do medicamento pela Secretaria de Saúde do Estado de São Paulo. Existem múltiplos aspectos ainda a serem analisados sobre esta forma de tratamento e suas conseqüências. No início da utilização, com base em levantamento de casos atendidos no Ambulatório de Gônadas e Desenvolvimento da Universidade Federal de São Paulo (Unifesp) (Figura 2), havia indicações indiretas de aquisição de considerável estatura final, entre $79 \%$ e $94 \%$ do alvo, estatura esta alcançada entre cinco meses até três anos de terapêutica.

Ainda que a maioria das pacientes com ST não tenha deficiência de hormônio de crescimento, a terapia com $\mathrm{GHr}$, quando utilizada de maneira adequada, melhora a altura final destas pacientes. Esta afirmação, anteriormente fundamentada em comparações de séries tratadas com séries históricas, foi adequadamente vali- 
dada em publicação randomizada, controlada (13). No referido estudo, utilizando-se uma dose de $0,9 \mathrm{UI} / \mathrm{kg} /$ semana, o ganho de estatura com o uso do GH por um período médio de 5,7 anos, quando comparado com o grupo-controle, foi de $7,2 \mathrm{~cm}$.

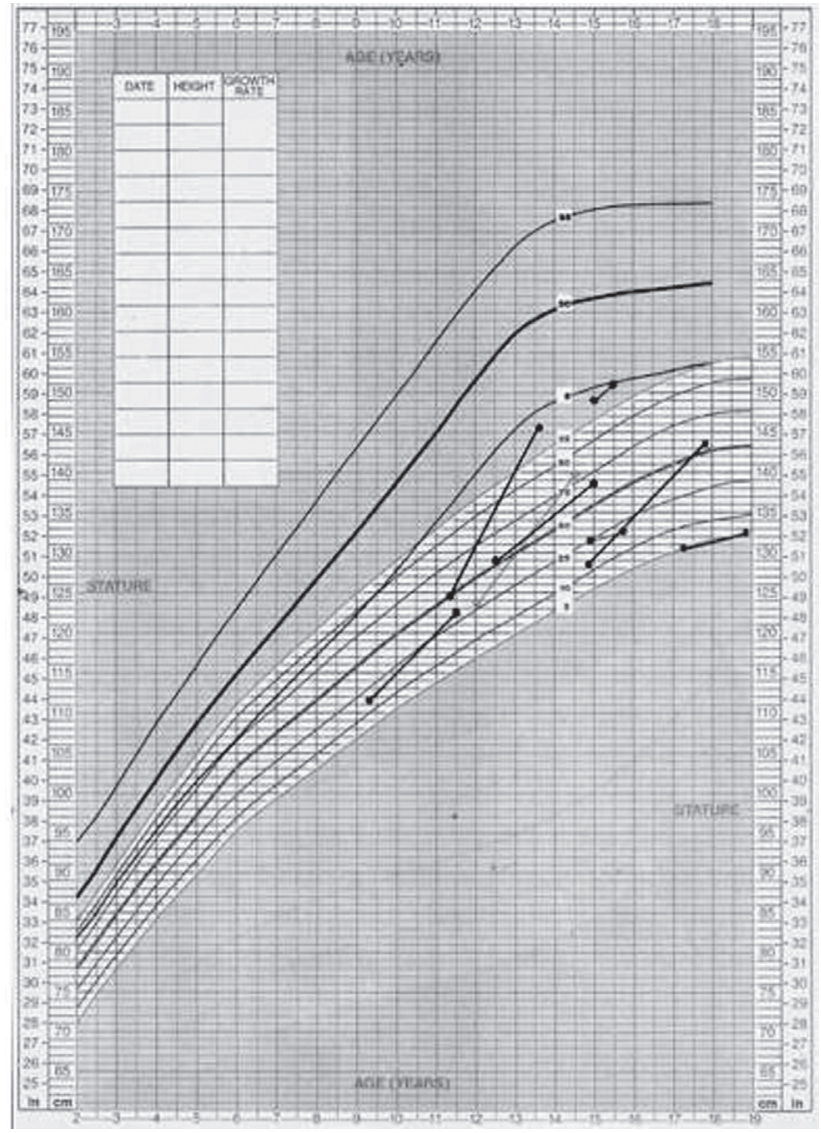

Figura 2. Desenvolvimento somático de meninas tratadas com hormônio de crescimento, acompanhadas em curvas próprias para a síndrome de Turner. (13).

O benefício do GHr na estatura final das pacientes depende do momento de início da terapêutica, da dose implementada e da duração do tratamento (14). Foi sugerida, também, como possível fator adicional para a potencialização do resultado, a via percutânea de oferta do estradiol na indução puberal (15).

Diversas diretrizes de grupos e sociedades nacionais e internacionais vêm sugerindo que o início da terapia com GH deve ocorrer quando a paciente com ST estiver abaixo do percentil cinco da curva de crescimento para meninas da mesma idade (16-19). Tal situação, correspondente ao desvio-padrão de estatu- ra menor que $-1,61 \mathrm{~m}$, pode ser detectada a partir do segundo ano de vida, conforme ilustrado por Davenport e cols. (3). Seja por diagnóstico tardio, falência em fazer pronta indicação ou, se for considerada a situação brasileira, dificuldades ou entraves burocráticos para obter oferta imediata da medicação após a indicação, a média de idade para início do GH tem sido elevada, como exemplificado em séries internacionais (20). Recentemente, foi analisada a proposta de antecipação do tratamento com $\mathrm{GHr}$, sendo este hormônio utilizado tão precocemente quanto aos 9 meses de vida (21). Ao avaliar prospectivamente, de maneira randomizada e controlada, o tratamento precoce determinou recuperação completa da deficiência estatural em 93\% das pacientes tratadas. As pacientes sem tratamento evoluíram com piora estatural progressiva.

O tratamento com GHr, além do impacto no crescimento somático, influencia de maneira positiva o comportamento psicossocial e a qualidade de vida das pacientes, sobretudo quando associado, no tempo adequado, à terapia estrogênica $(22,23)$.

Quanto ao momento apropriado para início da terapia de substituição hormonal ovariana, ainda que existam evidências para postergá-la com ganho adicional na altura pelo retardo do fechamento epifisário, a instituição de GHr por período suficientemente prolongado, antecedendo a idade cronológica de 12 anos, aparentemente não modifica, de modo significativo, $o$ prognóstico estatural $(24,25)$.

\section{SEGURANÇA}

Assim como em outras indicações, o tratamento que visa o crescimento com $\mathrm{GHr}$ não é isento de riscos e incertezas. Entre os efeitos colaterais descritos, alguns são identificados em outras condições com uso de somatotrofina. Outros, porém, são precipitados ou agravados pela referida medicação, interagindo com condições próprias da ST.

Em um grande estudo recente, os efeitos adversos da terapia com GH na ST foram avaliados prospectivamente e comparados com os identificados na deficiência de GH, insuficiência renal e baixa estatura idiopática. A incidência de certos efeitos adversos da terapia com $\mathrm{GHr}$, como hipertensão intracraniana, escoliose, deslocamento da epífise da cabeça femoral e pancreatite, foi maior em pacientes com ST. Novos casos de malignida- 
de em pacientes sem fatores de risco igualmente foram superiores nas mulheres com ST (26).

\section{O TRATAMENTO COM GH NA ST ESTÁ RELACIONADO COM O DESENVOLVIMENTO DE CÂNCER?}

O hormônio humano do crescimento (buman growth hormone - hrGH), fundamental para o crescimento, o desenvolvimento e a maturação sexual, tem sido extensivamente estudado desde seu isolamento, em 1944 (27). O hrGH é secretado pela hipófise e apresenta efeito direto na regulação somática do crescimento mediado pela interação com o seu receptor (GHR) $(28,29)$, agindo por estimulação da secreção hepática de IGF-1 (29) com importantes efeitos autócrinos e parácrinos. A secreção de hGH pela hipófise é estimulada pela liberação de GHRH (growth hormone releasing hormone) e ghrelina. A secreção de hGH foi determinada em muitos sítios, incluindo discreta população neural do sistema nervoso central (SNC), células endoteliais dos vasos sangüíneos, células epiteliais da glândula mamária e do timo e células do sistema imune, incluindo macrófagos, células $\mathrm{B}$, células $\mathrm{T}$ e células natural killer $(30,31)$.

Recentemente, grande número de publicações descreve a associação entre o hormônio do crescimento e o câncer, tanto em modelos animais quanto em humanos. Tais descrições incluem o aumento da incidência de câncer em pacientes com acromegalia $(32,33)$, alteração do risco de câncer associado com polimorfismos dos genes hGH/IGF-I (34-36) e aumento da expressão de hGH em anormalidades proliferativas humanas $(37,38)$. Além disso, sua influência sobre as atividades de oncogenes extensivamente relatadas em modelos animais, com a transformação oncogênica de células epiteliais mamárias em formações tumorais em camundongos com imunodeficiência, como resultado da ação autócrina da produção de hGH (39-41).

O papel do gene $I G F-I$ e seu receptor $I G F-I R$ na oncogênese é bem documentado. Diversos estudos epidemiológicos relataram a elevação dos níveis séricos de IGF-l associada com o aumento do risco de câncer de mama e próstata e do câncer colorretal em humanos (42-45). Além disso, a prolactina, hormônio hipofisário relacionado com o $\mathrm{GH}$, tem sido implicada no desenvolvimento de glândula mamária e na etiologia, tanto do carcinoma mamário quanto do câncer de próstata $(46,47)$.

Os estudos epidemiológicos também demonstraram correlação entre a altura e o aumento do risco de câncer, sugerindo que a elevação dos níveis circulantes de hrGH esteja associada à oncogênese, além de permitir associações entre o peso ao nascer, a altura e o desenvolvimento de cânceres $(48,49)$. A estatura elevada, tanto em crianças quanto em adultos, tem sido associada ao risco aumentado de câncer de mama, próstata, colorretal, hematopoiético e endometrial (48).

O risco de desenvolvimento de câncer é determinado pela combinação de fatores genéticos e efeitos ambientais, em particular dieta e estilo de vida. Sabe-se que o aumento de hGH circulante aumenta a expressão de $I G F-I$ que, por sua vez, tem sido implicado na gênese de diversos tipos de cânceres (42-45). Existem grandes evidências de que o hGH, pelo aumento da expressão de IGF-1, provê maior ligação entre esses fatores e o desenvolvimento de câncer por meio da sua influência na regulação da proliferação, da diferenciação e da apoptose celular. Sua expressão inapropriada parece contribuir para o crescimento, a manutenção e a progressão da maioria das neoplasias, incluindo câncer de mama, pulmão e cólon (50).

$\mathrm{O}$ aumento nos níveis séricos de hrGH pode ser conseqüência de produção tumoral ou mesmo exercer papel fundamental no desenvolvimento de tumores. No entanto, alguns estudos têm demonstrado a associação comum de polimorfismos no gene $G H I$ com neoplasias, sugerindo papel causal desses polimorfismos na carcinogênese. Além disso, interessantemente, SNPs (single nucleotide polymorphism - variação na seqüência de DNA em indivíduos da mesma espécie) na região promotora (região onde se inicia a transcrição) do gene GHI foi descrita como uma das maiores determinantes da expressão de $G H I(51,52)$.

As portadoras da ST apresentam aumento da mortalidade relacionado com a doença cardiovascular e distúrbios tireoidianos $(53,54)$. Embora ainda controverso (53), nessas pacientes, o risco de câncer está associado, principalmente, à presença do cromossomo $\mathrm{Y}$, íntegro ou não, que pode levar ao desenvolvimento de gonadoblastoma e/ou disgerminoma nas gônadas disgenéticas (55).

$\mathrm{O}$ tratamento com GHr está indicado para as portadoras de ST e os resultados têm sido satisfatórios. No entanto, os efeitos em longo prazo, provenientes desse tratamento, ainda são objeto de observação (56). 
As portadoras da ST apresentam grande variabilidade fenotípica e as razões para essa variabilidade não foram totalmente esclarecidas, o que leva à especulação de que o fenótipo na ST pode ser influenciado pela origem parental do cromossomo X. As diferenças físicas e as comportamentais entre indivíduos $45, \mathrm{X}$ com o cromossomo $\mathrm{X}$ paterno ou materno indicam a existência de loci imprintados geneticamente (57).

O imprinting genômico é um fenômeno referente à expressão diferencial de genes dependendo da origem parental. Acredita-se que tenha envolvimento em mamíferos na regulação da dosagem de genes relacionados com o desenvolvimento (27). Surpreendentemente, a maioria dos fetos abortados portadores da ST tem o cromossomo X de origem paterna, sugerindo papel importante do imprinting genético nessas perdas (58). Em humanos, a perda da regulação dos mecanismos de imprinting foi relacionada com as alterações de viabilidade de fetos, o crescimento fetal e pós-natal e o desenvolvimento neurológico e comportamental $(58,59)$. Além disso, as alterações nos mecanismos de imprinting podem ocasionar anormalidades no padrão de metilação do DNA, as quais foram verificadas em diversas neoplasias em humanos, principalmente, nos genes supressores de tumor, genes de reparo do DNA e nos genes inibidores de metástases (60).

Considerando que a detecção de seqüências cromossomo Y-específicas em pacientes com ST seja um fato necessário à prevenção do desenvolvimento de gonadoblastoma, a administração de hormônio do crescimento em pacientes portadoras de fragmentos do cromossomo Y pode levar ao desenvolvimento de tumores (61).

As portadoras de ST apresentam mosaicismo cromossômico em cerca de $40 \%$ dos casos. Os linfócitos de sangue periférico são, geralmente, o material de escolha para análise citogenética de pacientes com suspeita dessa síndrome, uma vez que esse tecido é facilmente obtido. No diagnóstico laboratorial, a análise citogenética clássica é feita, em geral, em 30 metáfases, o que pode detectar $10 \%$ de mosaicismo. Assim, este pode não ser detectado em pacientes que apresentem mosaicismo em uma freqüência menor que $10 \%$ nas células do sangue (62). Um outro problema a ser considerado constitui a análise de diferentes tecidos, uma vez que o mosaicismo pode não ser detectado no sangue periféri$\mathrm{co}$, mas pode ser significativo em amostras de tecidos com outras origens embrionárias (62-64).
Tradicionalmente, é recomendada que a pesquisa de fragmentos do cromossomo Y na ST deva ser realizada em apenas duas situações: quando há sinais de virilização e/ou quando há a presença de cromossomo marcador não identificado pela citogenética clássica (65-67). No entanto, Bianco e cols. (55) estudaram 20 pacientes com ST e cariótipo 45 , X por PCR (reação em cadeia da polimerase) em amostras de diferentes tecidos e encontraram que sete $(35 \%)$ das pacientes apresentaram mosaicismo oculto do cromossomo $\mathrm{Y}$ em pelo menos um dos tecidos estudados. Uma dessas pacientes desenvolveu gonadoblastoma bilateral, o que corrobora a recomendação de gonadectomia profilática quando há seqüências cromossomo Y-específicas. Nessa paciente, a presença de seqüências do cromossomo $\mathrm{Y}$ não estava associada à virilização, indicando que a ausência dessa característica não exclui a possibilidade de mosaicismo oculto envolvendo o cromossomo $\mathrm{Y}$.

Além disso, Guedes e cols. (68) reportaram o caso de uma menina com cariótipo $45, \mathrm{X} / 46, \mathrm{X}, \mathrm{der}(\mathrm{Y})$, que não apresentava sinais de virilização nem sinais clínicos da ST, exceto pela reduzida taxa de crescimento. Após gonadectomia profilática, por causa do risco de desenvolvimento de gonadoblastoma, as gônadas e a amostra de sangue periférico foram analisadas por FISH (hibridação in situ por fluorescência) e por PCR no intuito de detectar seqüências cromossomo Y-específicas. A análise mostrou que o cromossomo derivado era um isodicêntrico do braço curto do cromossomo $\mathrm{Y}$ - idic $(\mathrm{Yp})$ - e que havia diferença significativa de proporções de células contendo o cromossomo $\mathrm{Y}$ nos dois tecidos analisados. No sangue periférico, cerca de $97,5 \%$ das células apresentavam o cromossomo isodicêntrico de Yp com duplicação do gene $S R Y$. No entanto, isso não determinou nenhum sinal de desenvolvimento sexual masculino na paciente, porque nas gônadas $60 \%$ das células eram 45,X, demonstrando a importância do mosaicismo tecido-específico.

Um estudo retrospectivo, realizado na Grã-Bretanha, acompanhou 3.425 mulheres caracterizadas citogeneticamente como portadoras de ST, entre 1959 e 2002, com o intuito de comparar o risco de incidência de cânceres na síndrome e na população geral. Os autores observaram que a incidência de tumores do SNC, especialmente, meningioma e tumores de cérebro da infância foram significantemente aumentados nas portadoras da ST, bem como tumores de bexiga, de uretra e de olho. 
Em contrapartida, a incidência de câncer de mama foi diminuída entre as portadoras de ST, comparada com a população geral. Todas as mulheres com ST que apresentaram linhagem do cromossomo Y desenvolveram gonadoblastoma. Os autores apontam as causas genéticas, os fatores hormonais e os efeitos da terapia com hrGH como responsáveis pela incidência aumentada dos tumores mencionados anteriormente (69).

\section{CONCLUSÃo}

O hrGH é secretado pela hipófise e apresenta efeito direto na regulação somática do crescimento mediado pela interação com o seu receptor (GHR), agindo por estimulação da secreção hepática de IGF-l com importantes efeitos autócrinos e parácrinos. Recentemente, grande número de publicações descreveu a associação entre o hormônio do crescimento e o risco de câncer, tanto em modelos animais quanto em humanos.

As portadoras de síndrome de Turner apresentam aumento da mortalidade relacionada com a doença cardiovascular e os distúrbios tireoidianos. No entanto, nessas pacientes, o risco de câncer está associado, principalmente, à presença do cromossomo $\mathrm{Y}$, íntegro ou não, que pode levar ao desenvolvimento de gonadoblastoma e/ou disgerminoma nas gônadas disgenéticas. Além disso, as portadoras da ST apresentam grande variabilidade fenotípica, o que leva à especulação de que o fenótipo na ST pode ser influenciado pela origem parental do cromossomo X. As alterações nos mecanismos de imprinting podem ocasionar anormalidades no padrão de metilação do DNA, a qual foi verificada em diversas neoplasias em humanos, principalmente, nos genes supressores de tumor, genes de reparo do DNA e nos genes inibidores de metástase.

Dessa forma, a administração de GHr na ST deve ser feita com cautela. A constituição cromossômica e a possibilidade de mosaicismo oculto do cromossomo Y estão relacionadas ao desenvolvimento de gonadoblastoma. Vale ressaltar que o gonadoblastoma, apesar de ser um tumor benigno, pode evoluir para a forma maligna, o disgerminoma, em 60\% dos casos. Além disso, o padrão de metilação nas portadoras dessa síndrome ainda não é totalmente conhecido e pode levar à perda da regulação nos mecanismos de proliferação, diferenciação e apoptose celular, contribuindo para o crescimento, a manutenção e a progressão da maioria dos cânceres. Assim, independentemente dos benefícios que a terapia de hrGH possa trazer na estatura final das portadoras de ST, a investigação de seqüências do cromossomo $\mathrm{Y}$ deve ser realizada sem levar em consideração o cariótipo, bem como a gonadectomia profilática nos casos positivos para a presença de fragmentos do cromossomo $\mathrm{Y}$, conferindo maior segurança ao tratamento.

\section{REFERÊNCIAS}

1. Turner HH. A syndrome of infantilism, congenital webbed neck, and cubitus valgus. Endocrinology. 1938;23:566-74.

2. Gravholt $\mathrm{CH}$. Epidemiological, endocrine and metabolic features in Turner syndrome. Eur J Endocrinol. 2004;151(6):657-87.

3. Davenport ML, Punyasavatsut N, Stewart PW, Gunther DF, Savendahl L, Sybert VP. Growth failure in early life: an important manifestation of Turner syndrome. Horm Res. 2002;57(5-6):157-64.

4. Lyon AJ, Preece MA, Grant DB. Growth curve for girls with Turner syndrome. Arch Dis Child. 1985;60(10):932-5.

5. Ellison JW, Wardak Z, Young MF, Gehron RP, Laig-Webster M, Chiong W. PHOG, a candidate gene for involvement in the short stature of Turner syndrome. Hum Mol Genet. 1997;6(8):1341-7.

6. Ogata T, Matsuo N. Sex chromosome aberrations and stature: deduction of the principal factors involved in the determination of adult height. Hum Genet. 1993;91(6):551-62.

7. Rao E, Weiss B, Fukami M, Rump A, Niesler B, Mertz A, et al. Pseudoautosomal deletions encompassing a novel homeobox gene cause growth failure in idiopathic short stature and Turner syndrome. Nat Genet. 1997;16(1):54-63.

8. Blaschke RJ, Rappold G. The pseudoautosomal regions, SHOX and disease. Curr Opin Genet Dev. 2006;16(3):233-9.

9. Leka SK, Kitsiou-Tzeli S, Kalpini-Mavrou A, Kanavakis E. Short stature and dysmorphology associated with defects in the SHOX gene. Hormones (Athens). 2006;5(2):107-18.

10. Blaschke RJ, Rappold GA. SHOX: growth, Leri-Weill and Turner syndromes. Trends Endocrinol Metab. 2000;11(6):227-30.

11. Ross JL, Scott C Jr., Marttila P, Kowal K, Nass A, Papenhausen $P$, et al. Phenotypes associated with SHOX deficiency. J Clin Endocrinol Metab. 2001;86(12):5674-80.

12. Rappold G. SHOX: a geneticist's view. J Clin Endocrinol Metab 2002;87(4):1911-2.

13. Witzler AP, Mendes JRT, Verreschi ITN. Desenvolvimento somático de meninas com síndrome de Turner tratadas com hormônio de crescimento. VI Congresso Iniciação Científica PIBIC/ CNPq Unifesp, 1998.

14. Stephure DK. Impact of growth hormone supplementation on adult height in turner syndrome: results of the Canadian randomized controlled trial. J Clin Endocrinol Metab. 2005;90(6):3360-6.

15. van Pareren YK, de Muinck Keizer-Schrama SM, Stijnen T, Sas TC, Jansen M, Otten BJ, et al. Final height in girls with turner syndrome after long-term growth hormone treatment in three dosages and low dose estrogens. J Clin Endocrinol Metab. 2003;88(3):1119-25.

16. Soriano-Guillen L, Coste J, Ecosse E, Léger J, Tauber M, Cabrol S, et al. Adult height and pubertal growth in Turner syndrome after treatment with recombinant growth hormone. J Clin Endocrinol Metab. 2005;90(9):5197-204. 
17. Gharib H, Cook DM, Saenger PH, et al. American Association of Clinical Endocrinologists medical guidelines for clinical practice for growth hormone use in adults and children-2003 update. Endocr Pract. 2003;9(1):64-76.

18. Guedes AD, Verreschi ITN. Síndrome de Turner: diagnóstico e tratamento. Projeto Diretrizes 5. 2006. Ref Type: electronic citation.

19. Saenger P, Wikland KA, Conway GS, Davenport M, Gravholt $\mathrm{CH}$, Hintz $\mathrm{R}$, et al. Recommendations for the diagnosis and management of Turner syndrome. J Clin Endocrinol Metab. 2001;86(7):3061-9.

20. Stratakis CA, Rennert OM. Turner Syndrome an update. Endocinologist. 2005;15(1):27-36.

21. Parker KL, Wyatt DT, Blethen SL, Baptista J, Price L. Screening girls with Turner syndrome: The National Cooperative Growth Study Experience. J Pediatr. 2003;143(1):133-5.

22. Davenport ML, Crowe BJ, Travers SH, Rubin K, Ross JL, Fechner PY, et al. Growth hormone treatment of early growth failure in toddlers with Turner syndrome: a randomized, controlled, multicenter trial. J Clin Endocrinol Metab. 2007;92(9):3406-16.

23. Bannink EM, Raat $H$, Mulder PG, de Muinck Keizer-Schrama SM. Quality of life after growth hormone therapy and induced puberty in women with Turner syndrome. J Pediatr. 2006; 148(1):95-101.

24. van Pareren YK, Duivenvoorden HJ, Slijper FM, Koot HM, Drop SL, de Muinck Keizer-Schrama SM. Psychosocial functioning after discontinuation of long-term growth hormone treatment in girls with Turner syndrome. Horm Res. 2005;63(5): 238-44.

25. Chernausek SD, Attie KM, Cara JF, Rosenfeld RG, Frane J. Growth hormone therapy of Turner syndrome: the impact of age of estrogen replacement on final height. Genentech, Inc., Collaborative Study Group. J Clin Endocrinol Metab. 2000;85(7):2439-45.

26. Reiter EO, Blethen SL, Baptista J, Price L. Early initiation of growth hormone treatment allows age-appropriate estrogen use in Turners syndrome. J Clin Endocrinol Metab. 2001;86(5):1936-41.

27. Lee JT. Molecular links between X-inactivation and autosomal imprinting: $X$-inactivation as a driving force for the evolution of imprinting? Curr Biol. 2003;13:R242-54.

28. Zhu T, Goh E L, Graichen R, Ling L, Lobie PE. Signal transduction via the growth hormone receptor. Cell Signall. 2001;13:599-616.

29. Le Roith D, Scavo L, Butler A. What is the role of circulating IGF-I? Trends Endocrinol Metab. 2001;12:48-52.

30. Liu N, Mertani HC, Norstedt G, Tornell J, Lobie PE. Mode of the autocrine/paracrine mechanism of growth hormone action. Exp Cell Res. 1997;237:196-206.

31. Harvey S, Hull KL. Growth hormone. A paracrine growth factor? Endocrine. 1997;7:267-79.

32. Webb SM, Casanueva F, Wass JA. Oncological complications of excess GH in acromegaly. Pituitary. 2002;5:21-5.

33. Siegel G, Tomer Y. Is there an association between acromegaly and thyroid carcinoma? A critical review of the literature. Endoc Res. 2005;31:51-8.

34. Marchand L, Donlon T, Seifried A, Kaaks R, Rinaldi S, Wilkens LR. Association of a common polymorphism in the human GH1 gene with colorectal neoplasia. J Natl Cancer Inst. 2002;94:454-60.

35. Wagner K, Hemminki K, Grzybowska E, Klaes R, Chen B, Butkiewicz $D$, et al. Association of polymorphism and haplotypes in the human growth hormone $1(\mathrm{GH} 1)$ gene with breast cancer. Endocr Relat Cancer. 2005;12:917-28.

36. Wagner K, Hemminki K, Grzybowska E, Bermejo JL, Butkiewi$\mathrm{cz} \mathrm{D}$, Pamula J, et al. Polymorphism in the growth hormone receptor: a case-control study in breast cancer. Int $\mathrm{J}$ Cancer. 2006;118:2903-6.

37. Mertani HC, Garcia-Caballero T, Lambert A, Gerard F, Palayer C, Boutin JM, et al. Cellular expression of growth hormone and prolactin receptors in human breast disorders. Int $\mathrm{J}$ Cancer. 1998;79:202-11.

38. Raccurt M, Lobie PE, Moudilou E, Garcia-Caballero T, Frappart L, Morel G, et al. High stromal and epithelial human GH gene expression is associated with proliferative disorders of the mammary gland. J Endocrinol. 2002;175:307-18.

39. Kaulsay KK, Mertani HC, Tornell J, Morel G, Lee KO, Lobie PE. Autocrine stimulation of human mammary carcinoma cell proliferation by human growth hormone. Exp Cell Res. 1999;250:35-50.

40. Mukhina S, Mertani HC, Guo K, Lee KO, Gluckman PD, Lobie $\mathrm{PE}$. Phenotype conversion of human mammary carcinoma cells by autocrine human growth hormone. Proc Natl Acad Sci U S A. 2004;101:15166-71.

41. Zhu T, Starling-Emerald B, Zhang X, Lee K O, Gluckman PD, Mertani HC, et al. Oncogenic transformation of human mammary epithelial cells by autocrine human growth hormone. Cancer Res. 2005;65:317-24.

42. Khandwala HM, McCutcheon IE, Flyvbjerg A, Friend KE. The effects of insuline-like growth factors on tumorigenesis and neoplastic growth. Endocr Rev. 2000;21:215-44.

43. Baserga R, Peruzzi F, Reiss K. The IGF-I receptor in câncer biology. Int J Cancer. 2003;107:873-7.

44. Laban C, Bustin SA, Jenkins PJ. The GH-IGF-I axis and breast cancer. Trends Endocrinol Metab. 2003;14:38-4.

45. Yakar S, Leroith D, Brodt P. The role of growth hormone/insuline-like growth factor axis in tumor growth and progression: lessons from animal models. Cytokine Growth Factor Rev. 2005;16:407-20.

46. Wennbo H, Tornell J. The role of prolactin and growth hormone in breast cancer. Oncogene. 2000;19:1072-6.

47. Goffin V, Bernichtein S, Touraine P, Kelly PA. Development and potencial clinical uses of human prolactin receptor antagonists. Endocr Rev. 2005;26:400-22.

48. Okasha M, Gunnell D, Holly J, Davey Smith GD. Childhood growth and adult cancer. Best Pract Res Clin Endocrinol Metab. 2002;16:225-41.

49. Lawlor DA, Okasha M, Gunnell D, Holly J, Davey Smith GD, Ebrahim S. Associations of adult measures of childhood growth with breast cancer: findings from the British Women's Heart and Heath Study. Br J Cancer. 2003;89:81-7.

50. Jenkins PJ, Bustin SA. Evidence for a link between IGF-I and cancer. Eur J Endocrinol. 2004;151:17-22.

51. Horan M, Newsway V, Yasmin, Lewis MD, Easter TE, Rees DA. Genetic variation at the growth hormone (GH1) and growth hormone receptor (GHR) loci as a risk factor for hypertension and stroke. Hum Genet. 2006;119:527-40.

52. Ren Z, Cai Q, Shu XO, Cai H, Cheng JR, Wen WO, et al. Genetic polymorphisms in the human growth hormone-1 gene (GH1) and the risk of breast carcinoma. Cancer. 2004;101:251-7.

53. Gravholt $\mathrm{CH}$, Christian Klausen I, Weeke J, Sandahl Christiansen J. Lp(a) and lipids in adult Turner's syndrome: impact of treatment with 17 beta-estradiol and norethisterone. Atherosclerosis. 2000;150:201-8. 
54. Gravholt $\mathrm{CH}$. Epidemiological, endocrine and metabolic features in Turner syndrome. Eur J Endocrinol. 2004;151:657-87.

55. Bianco B, Lipay MV, Melarano MI, Guedes AD, Verreschi ITN. Detection of hidden $Y$ mosaicism in Turner's syndrome: importance in the prevention of gonadoblastoma. J Pediatr Endocrinol Metab. 2006;19(9):1113-7.

56. Cabanas P, García-Caballero T, Barreiro J, Castro-Feijóo L, Gallego $R$, Arévalo $T$, et al. Papillary thyroid carcinoma after recombinant GH therapy for Turner syndrome.Eur J Endocrinol. 2005;153:499-502.

57. Sagi L, Zuckerman-Levin N, Gawlik A, Ghizzoni L, Buyukgebiz $A$, Rakover $Y$, et al. Clinical significance of the parental origin of the $\mathrm{X}$ chromosome in turner syndrome. J Clin Endocrinol Metab. 2007;92:846-52.

58. Wrzeska M, Rejduch B. Genomic imprinting in mammals. J Appl Genet. 2004;45:427-33.

59. Reik W, Walter J. Genomic imprinting: parental influence on the genome. Nat Rev Genet. 2001;2:21-32.

60. Nygren AO, Ameziane N, Duarte HM, Vijzelaar RN, Waisfisz Q, Hess CJ, et al. Methylation-specific MLPA (MS-MLPA): simultaneous detection of $\mathrm{CpG}$ methylation and copy number changes of up to 40 sequences. Nucleic Acids Res. 2005;33:128.

61. Rosen, GF, Kaplan, B, Lobo, RA. Menstrual function and hirsutism in patients with gonadal dysgenesis. Obstetrics and Gynecology. 1988;71: 677-80.

62. Quilter CR, Taylor K, Conway GS, Nathwani N, Delhanty JD. Cytogenetic and molecular investigations of $Y$ chromosome sequences and their role in Turner syndrome. Ann Hum Genet. 1998;99-106.

63. Hanson L, Bryman I, Barrenas ML, Janson PO, Wahlstrom J, Albertsson-Wikland K, et al. Genetic analysis of mosaicism in 53 women with Turner syndrome. Hereditas. 2001;134(2):153-9.
64. Hanson L, Bryman I, Jason PO, Jakobsen AM, Hanson C. Fluorescence in situ hybridisation analysis and ovarian histology of women with Turner syndrome presenting with Y-chromosomal material: a correlation between oral epithelial cells, lymphocytes and ovarian tissue. Hereditas. 2002;137(1):1-6.

65. Frias JL, Davenport ML. Health supervision for children with Turner syndrome. Pediatrics. 2003;3:692-702.

66. Saenger P, Wikland KA, Conway GS, Davenport M, Gravholt $\mathrm{CH}$, Hintz R, et al. Fifth International Symposium on Turner Syndrome. Recommendations for the diagnosis and management of Turner syndrome. J Clin Endocrinol Metab. 2001;86:3061-9.

67. Stratakis CA, Rennert OM. Turner syndrome: an update. Endocrinologist. 2005;1:27-36.

68. Guedes AD, Bianco B, Lipay MVN, Brunoni D, de Lourdes Chauffailli M, Verreschi ITN. Determination of the sexual phenotype in a child with $45, X / 46, X$, Idic(Yp) mosaicism: importance of the relative proportion of the $45, X$ line in gonadal tissue. Am J Med Genet. A 2006;140:1871-5.

69. Schoemaker MJ, Swerdlow A, Higgins CD, Wright AF, Jacob PA. Cancer incidence in women with Turner syndrome in Great Britain: a national cohort study. Lancet. 2008;9:239-46.

\section{Endereço para correspondência:}

leda T. N. Verreschi

Laboratório de Esteróides

Rua Pedro de Toledo, 781, $13^{\circ}$ andar

04039-032 São Paulo, SP

E-mail: ieda.verreschi@unifesp.br 